\title{
Bilateral adrenal myelolipomas presenting as acute adrenal insufficiency in an adult with congenital adrenal hyperplasia
}

\author{
Sakolwan Suchartlikitwong, ${ }^{1}$ Rahul Jasti, ${ }^{2}$ Joaquin Lado-Abeal, ${ }^{3}$ \\ Ana Marcella Rivas Mejia ${ }^{3}$
}

'Internal Medicine, Texas Tech University Health Sciences Centre, Lubbock, Texas, USA ${ }^{2}$ Radiology, Texas Tech University Health Sciences Centre, Lubbock, Texas, USA ${ }^{3}$ Department of Internal Medicine, division of Endocrinology, Texas Tech University Health Sciences Centre School of Medicine, Lubbock, Texas, USA

Correspondence to Ana Marcella Rivas Mejia, marcella.rivas@ttuhsc.edu

Accepted 26 November 2018

Check for updates

(c) BMJ Publishing Group Limited 2019. No commercial re-use. See rights and permissions. Published by BMJ.

To cite: Suchartlikitwong $S$,

Jasti R, Lado-Abeal J,

et al. BMJ Case Rep

2019:12:e226826

doi:10.1136/bcr-2018-

226826

\section{SUMMARY}

Adrenal myelolipomas are relatively rare tumours composed of adipocytes and myeloid cells that arise in response to chronic adrenocorticotropic hormone stimulation. We present the case of bilateral adrenal myelolipomas in a 39-year-old man with untreated congenital adrenal hyperplasia (CAH) presenting with acute adrenal insufficiency and severe virilisation. Phenotypically, he is a man of short stature and has hyperpigmentation of the skin, gingiva and nail beds. Genital examination revealed micropenis and no palpable testes. Laboratory testing was consistent with primary adrenal insufficiency. An abdominal CT showed bilateral adrenal myelolipomas. An MRI of the pelvis revealed female reproductive organs. Chromosome study showed a karyotype of 46,XX. A CYP21A2 gene mutation confirmed diagnosis of $\mathrm{CAH}$ with 21-hydroxylase deficiency. The patient was treated with stress dose corticosteroids, subsequently tapered to physiological doses. We review previously reported cases and discussed diagnosis and treatment, including hormonal therapy and psychological approach.

\section{BACKGROUND}

Adrenal myelolipomas (AMs) are relatively rare, benign tumours composed of adipocytes and myeloid cells that result from reticuloendothelial cell metaplasia in response to chronic stimuli. We present a case of bilateral AMs in a patient with untreated congenital adrenal hyperplasia $(\mathrm{CAH})$ presenting in late adulthood with an acute adrenal crisis and severe virilisation.

\section{CASE PRESENTATION}

A 39-year-old, Hispanic adult who was born outside the USA and raised as a man, presented to the emergency department with generalised weakness, nausea and vomiting. On presentation, his blood pressure was $84 / 56 \mathrm{~mm} \mathrm{Hg}$, heart rate was 91 beats per minute and body temperature was $97.1^{\circ} \mathrm{F}\left(36.2^{\circ} \mathrm{C}\right)$. The patient was phenotypically a muscular male of short stature with a height of $140 \mathrm{~cm}$. On physical examination, he was noted to have hyperpigmentation of the skin, gingiva and nail beds (figure 1). Genital examination revealed a micropenis with hypospadias, and no palpable testes.

\section{INVESTIGATIONS}

A random serum cortisol level was $2.48 \mu \mathrm{g} /$ $\mathrm{dL}$ and adrenocorticotropic hormone (ACTH) was $10445 \mathrm{pg} / \mathrm{mL}$ (normal range: $6-50 \mathrm{pg} / \mathrm{mL}$ ). Serum sodium was $132 \mathrm{mmol} / \mathrm{L}$ (normal range: $136-145 \mathrm{mmol} / \mathrm{L}$ ) and potassium was $5.0 \mathrm{mmol} / \mathrm{L}$ (normal range: $3.5-5.1 \mathrm{mmol} / \mathrm{L}$ ). CT and MRI of the abdomen showed adrenal masses of $6 \times 4.5$ $\times 5 \mathrm{~cm}$ (craniocaudal $\times$ anteroposterior $\times$ width) on the right and $2.3 \times 1.4 \times 2.5 \mathrm{~cm}$ on the left. The masses exhibited radiological characteristics of myelolipomas (figure 2). Magnetic resonance of the pelvis revealed a uterus, bilateral ovaries and clitoromegaly (figure 3). An ACTH stimulation test confirmed adrenal insufficiency, with serum cortisol level at baseline of $1.06 \mu \mathrm{g} / \mathrm{dL}$, at $30 \mathrm{~min} 0.86 \mu \mathrm{g} /$ $\mathrm{dL}$ and at $60 \mathrm{~min} 0.72 \mu \mathrm{g} / \mathrm{dL}$. A serum baseline 17-hydroxyprogesterone level was high at $2003 \mathrm{ng} /$ dL. Due to sampling error, 17-hydroxyprogesterone levels were not drawn after Cortrosyn administration. Karyotype analysis revealed a 46,XX genotype, and a CYP21A2 gene mutation analysis identified a compound heterozygous R356W and intron $2 \mathrm{G}$ mutation.

\section{TREATMENT}

The patient was treated with supraphysiological 'stress dose' corticosteroids, slowly tapered to physiological doses. He improved and was discharged with oral hydrocortisones. He is scheduled for a follow-up as an outpatient to discuss more about testosterone replacement.

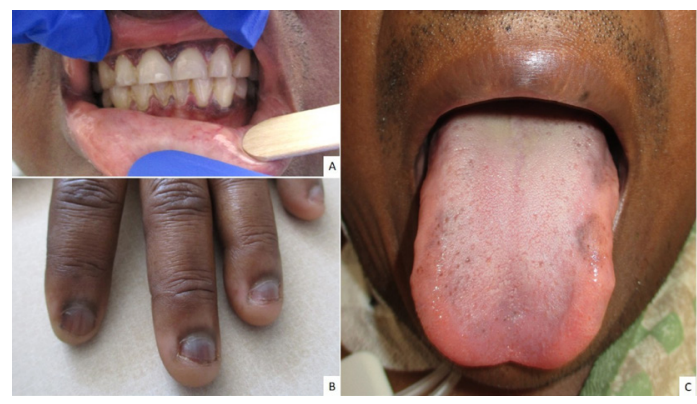

Figure 1 Hyperpigmentation of gingiva $(A)$, nail beds (B) and tongue (C). 


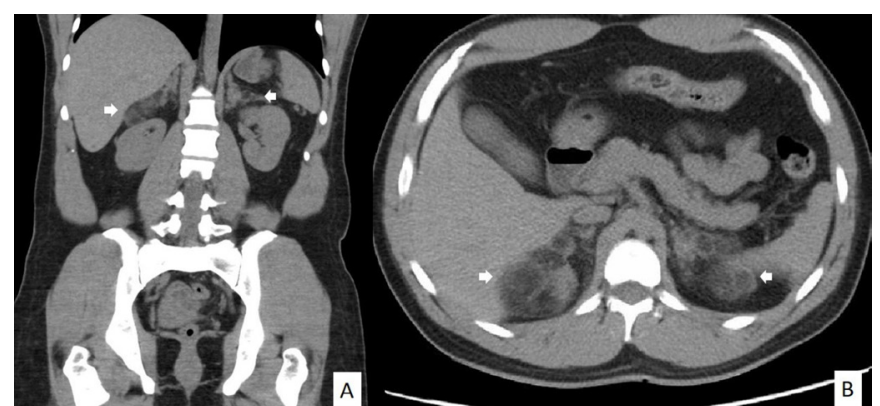

Figure 2 A coronal (A) and axial (B) non-contrast CT scan of the abdomen demonstrates adrenal masses in the right and left suprarenal regions (arrows) with macroscopic fat and soft tissue density within them.

\section{OUTCOME AND FOLLOW-UP}

The patient identifies himself as a male; he is married to a female partner. We had planned to start testosterone replacement and make arrangements for genitourinary surgery after discharge, but the patient has missed several follow-up appointments afterwards.

\section{DISCUSSION}

AMs are benign tumours composed of adipose tissue and haematopoietic cells. They are the second most common primary adrenal incidentalomas (AI) accounting for 6\%-16\% of such lesions. ${ }^{1}$ Since AMs are often asymptomatic and non-secreting, they are usually found incidentally on radiographic imaging studies. The diagnosis can be established by radiological characteristics that consist of a well-circumscribed mass with a mixture of adipose tissue and myeloid cell attenuation.

It is hypothesised that AMs result from altered haematopoietic cell functioning and hormonal stimuli. ${ }^{1}$ Conditions with high circulating ACTH, such as is the case of untreated $\mathrm{CAH}$, have been associated with AI, and AM specifically. ${ }^{23}$ Chronic stimulation of the adrenal tissue leads to adrenal cortex hyperplasia and subsequently the formation of adrenal tumours. Adrenal nodules have been reported in $45 \%$ of $\mathrm{CAH}$ carriers. ${ }^{4}$ A systematic review and meta-analysis reported a frequency of CAH in an AI cohort that is higher than that of the general population $(5.9 \%$ based on a biochemical diagnosis and $0.8 \%$ based on a genetic diagnosis). ${ }^{4}$ In this cohort, more than half of the patients with genetically proven $\mathrm{CAH}$ presented with bilateral AIs. Similarly, in a systemic review that included 420 cases of AM, $10 \%$ of the cases were determined to be associated with CAH. ${ }^{1}$ With this in consideration, testing for $\mathrm{CAH}$ is recommended as part of the evaluation in patients with AI with clinical findings suggestive of $\mathrm{CAH}$.

The management of AM is usually conservative. The American Association of Clinical Endocrinologists and American Association of Endocrine Surgeons medical guidelines 2009 for AIs recommended against a hormonal work-up of a newly discovered AM. ${ }^{5}$ However, a small number of AMs are associated with endocrine disorders, including $\mathrm{CAH}$, primary aldosteronism, hypercortisolism and hyperandrogenism. ${ }^{1}$ It is recommended to use clinical judgement to determine the need of hormonal work-up. A small-size AM (less than $4 \mathrm{~cm}$ ) can be observed with interval radiological surveillance, while adrenalectomy is recommended for larger tumours (more than $4 \mathrm{~cm}$ ) or for lesions that result in symptoms due to compression of adjacent structures.

This patient's presentation is reminiscent of the patient reported by Luigi De Crecchio in 1865, describing the first case

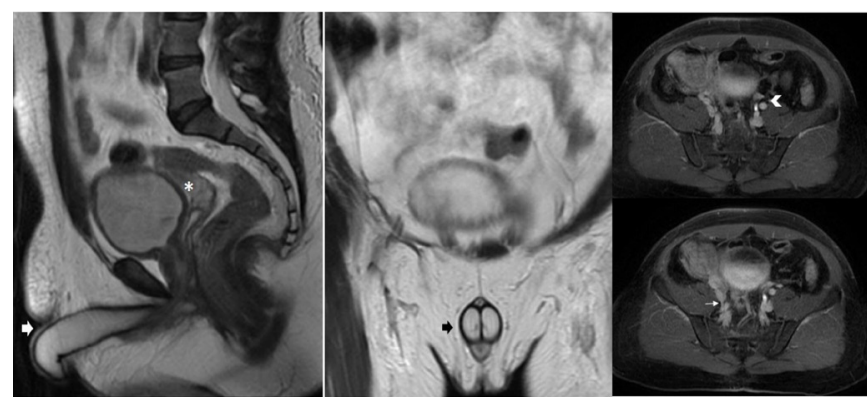

Figure $3 \mathrm{MRI}$ of the pelvis demonstrates a normally formed uterus (asterisk) and a clitoromegaly in a sagittal view (thick white arrow) and a coronal view (thick black arrow). Bilateral ovaries are hypoplastic (thin arrow and arrow head).

of a non-salt wasting CAH patient, it was translated into English version by Delle Piane et al. ${ }^{6}$ The author described the patient who lived as a man and had a nearly normal appearing male external genitalia but found to have female internal reproductive organs and bilateral enlarged adrenals during a postmortem autopsy. A similar case of 21-hydroxylase deficiency CAH female presented with a $10 \times 7 \mathrm{~cm}$ left AM who had short stature, hyperpigmentation, hirsutism, ambiguous genitalia and primary amenorrhea. ${ }^{7}$ Our patient was diagnosed with CAH late in life; the delay in diagnosis could be due to a mild degree of hormonal deficiency. Under these circumstances, it is usually a stress insult such as dehydration that precipitates an adrenal crisis and leads the patient to seek medical attention. In the USA, universal newborn screening for 21-hydroxylase deficiency has been implemented nationwide since 2010, allowing early detection and treatment of patients who have $\mathrm{CAH}^{8}{ }^{8}$ It must be acknowledged though that a non-classic form of $\mathrm{CAH}$ may be missed by neonatal screening. ${ }^{9}$ Our patient was born outside the USA and subsequently did not have newborn screening, additionally he had limited access to medical care growing up.

There are various mutations in CYP21A gene resulting in $\mathrm{CAH}$. Our patient is a compound heterozygous for CYP21A gene mutations, intron $2 \mathrm{G}$ and $\mathrm{R} 356 \mathrm{~W}$. Intron $2 \mathrm{G}$ is a highly prevalent mutation, A-to-G change, located in the second intron of CYP21A gene that affects pre-mRNA splicing and results in some residual enzyme activity. ${ }^{10} \mathrm{R} 356 \mathrm{~W}$ mutation also has a relatively high prevalence leading to complete absence of enzyme activity and usually is associated with the salt-wasting form. ${ }^{11}$ Intron $2 \mathrm{G}$ and R356W compound heterozygous combination have been previously described in phenotypical males and females who present with the expected classic salt-wasting CAH. Nevertheless, there are cases of intron $2 \mathrm{G}-\mathrm{R} 356 \mathrm{~W}$ heterozygous mutations presenting a simple virilising phenotype without obvious salt wasting as our case. ${ }^{11}$

Gender assignment in virilised 46,XX $\mathrm{CAH}$ patients is a difficult and delicate issue. The patient in a case report by $\mathrm{De}$ Crecchio suffered psychologically from social pressure about conflicting gender and embarrassment about genital appearance. ${ }^{6}$ Early detection of this disorder prompts physicians and family to assign gender identity and assist sexual characteristic development. Undiagnosed CAH newborns are usually reared males because of virilised external genitalia. When diagnosis is made after male gender identity has established, the majority of patients remain to live as a male. A descriptive study of twelve 46,XX adult CAH patients reported long-term female partners with a strong libido and frequent orgasmic sexual activity in nine patients. ${ }^{12}$ All men in the study were treated with steroids and 
testosterone therapy. Two patients were reassigned to female gender during infancy and underwent feminising surgery. They were later self-reassigned to male gender due to dissatisfaction of living as females. A case series by Khattab et al reported three 46,XX CAH patients. ${ }^{13}$ Two patients, who were assigned to male gender and underwent surgical removal of female reproductive organs and male genitoplasty, showed satisfaction in regard to male gender role and behaviour. Our patient did express interest in male genitoplasty and testosterone replacement but he has missed his follow-up appointments.

In conclusion, bilateral AMs are associated with untreated $\mathrm{CAH}$ and chronic ACTH stimulation. Small-size myelolipomas are asymptomatic and can be expectantly monitored. However, larger size tumours can cause haemorrhage and become symptomatic. Early detection of $\mathrm{CAH}$ in newborn by universal screening and prompt hormonal replacement are the keys to reduce morbidity and mortality in individuals suffering from $\mathrm{CAH}$. If diagnosis is made after gender identity has established, male hormone replacement and surgical removal of female reproductive organs are options for 46, XX adults who are reared male.

\section{Learning points}

- Early detection of congenital adrenal hyperplasia (CAH) in newborns by universal screening and prompt hormonal replacement are keys to reduce morbidity and mortality in individuals suffering from CAH. Potential complications of untreated CAH include adrenal crisis and development of bilateral AMs.

- Untreated CAH female patients with virilised external genitalia are usually reared as males and may identify themselves as males. Testosterone replacement and genitoplasty should be offered to these patients.

Acknowledgements We would like to thank Dr Kenneth Nugent for the critical reading.

Contributors SS gathered information and wrote the manuscript. RJ provided CT and MRI images and description. JL-A and AMRM revised the manuscript and provided an expert opinion.
Funding The authors have not declared a specific grant for this research from any funding agency in the public, commercial or not-for-profit sectors.

Competing interests None declared.

Patient consent for publication Obtained.

Provenance and peer review Not commissioned; externally peer reviewed.

\section{REFERENCES}

1 Decmann A, Perge P, Tóth M, et al. Adrenal myelolipoma: a comprehensive review. Endocrine 2018;59:7-15.

2 Sieber SC, Gelfman NA, Dandurand R, et al. Ectopic ACTH and adrenal myelolipoma. Conn Med 1989;53:7-10.

3 Chakraborty PP, Patra S, Biswas SN, et al. Adrenal myelolipoma(s) as presenting manifestation of subclinical Cushing's disease (eutopic ACTH-dependent Cushing's syndrome). BMJ Case Rep 2017;2017:bcr-2017-221674.

4 Falhammar H, Torpy DJ. Congenital adrenal hyperplasia due to 21-hydroxylase deficiency presenting as adrenal incidentaloma: a systematic review and metaanalysis. Endocr Pract 2016;22:736-52.

5 Zeiger MA, Thompson GB, Duh QY, et al. The American Association of Clinical Endocrinologists and American Association of Endocrine Surgeons medical guidelines for the management of adrenal incidentalomas. Endocr Pract 2009:15:1-20

6 Delle Piane L, Rinaudo PF, Miller WL. 150 years of congenital adrenal hyperplasia: translation and commentary of De Crecchio's classic paper from 1865. Endocrinology 2015;156:1210-7.

7 Mallappa A, Millo CM, Quezado M, et al. Congenital adrenal hyperplasia presenting as an adrenal mass with increased ${ }^{18} \mathrm{f}$-fdg positron emission tomography uptake. J Endocr Soc 2017:1:1110-2.

8 Speiser PW, Azziz R, Baskin LS, et al. Congenital adrenal hyperplasia due to steroid 21-hydroxylase deficiency: an Endocrine Society clinical practice guideline. J Clin Endocrinol Metab 2010:95:4133-60.

9 Falhammar $\mathrm{H}$, Nordenström A. Nonclassic congenital adrenal hyperplasia due to 21-hydroxylase deficiency: clinical presentation, diagnosis, treatment, and outcome. Endocrine 2015;50:32-50.

10 Speiser PW, Dupont J, Zhu D, et al. Disease expression and molecular genotype in congenital adrenal hyperplasia due to 21-hydroxylase deficiency. J Clin Invest 1992:90:584-95.

11 Stikkelbroeck NM, Hoefsloot LH, de Wijs IJ, et al. CYP21 gene mutation analysis in 198 patients with 21-hydroxylase deficiency in The Netherlands: six novel mutations and a specific cluster of four mutations. J Clin Endocrinol Metab 2003:88:3852-9.

12 Lee $P A$, Houk CP, Husmann DA. Should male gender assignment be considered in the markedly virilized patient With 46,XX and congenital adrenal hyperplasia? J Urol 2010;184:1786-92

13 Khattab A, Yau M, Qamar A, et al. Long term outcomes in 46, XX adult patients with congenital adrenal hyperplasia reared as males. I Steroid Biochem Mol Biol 2017;165:12-17

Copyright 2019 BMJ Publishing Group. All rights reserved. For permission to reuse any of this content visit

https://www.bmj.com/company/products-services/rights-and-licensing/permissions/

BMJ Case Report Fellows may re-use this article for personal use and teaching without any further permission

Become a Fellow of BMJ Case Reports today and you can:

- Submit as many cases as you like

- Enjoy fast sympathetic peer review and rapid publication of accepted articles

- Access all the published articles

- Re-use any of the published material for personal use and teaching without further permission

For information on Institutional Fellowships contact consortiasales@bmjgroup.com

Visit casereports.bmi.com for more articles like this and to become a Fellow 